special field alone. The operating is a matter for the surgeon, anaesthetics for the anaesthetist, etc. But a team concept that has built up in psychiatry calls for the whole team operating at the operating site with collective decision-making, etc. We can picture the end result for the patient! A curious element also in the psychiatric team is that the psychiatrist, while apparently no more expert than the rest of the team, claims a medical salary usually considerably higher than that of the other team members. He may claim, "I can give drugs". But this function, in some circumstances, is being claimed also by the nurse and the clinical psychologist.

The term "psychiatrist" is unashamedly iatrogenic and Dr Child, as such, may share the claim to be a "healer of the psyche". If psychiatrists feel their expertise in psychopathology needs improvement then they should concentrate on research and training for medical colleagues leading to increasingly high standards of practice. But to indulge in cosy popularity from less well trained practitioners at the price of exposing patients to lower standards of care is unethical. Patients pay dearly for the multidiscipline, multi-agency practice on all the continents. The Royal College of Psychiatrists has a duty to protect its members and it will neglect these issues at its peril.

Hill House

Higham, Colchester

CO7 6LD

JOHN HOWELLS

\section{Who cares for the adult brain-damaged}

DeAr SIRS

Shawcross (1990) described Hamble Ward - a unit for adult brain-damaged indviduals with behavioural problems in Southampton. A similar unit, Heddiw (Welsh for today) Ward, was set up in Whitchurch Hospital, Cardiff in 1988, and has received 40 referrals ( 20 admissions). Causes for the brain injuries of the admissions include: traumatic head injury (5), cerebrovascular disease (6), Huntington's chorea (4), presenile dementia of Alzheimer type (3), Herpes Simplex Encephalitis Amnestic syndrome (1) and hypoxic brain damage (1).

Thirteen admissions were male and seven female; the age range was 29-70 years (mean for males 54.9 , for females 56.3). The time interval from onset of the brain insult/diagnosis to admission ranged from two months to ten years (mean 3.3 years). Referrals were from general psychiatric wards (4), the district rehabilitation unit (2), medical wards (4), and the community (5). A wide range of behavioural problems were seen - depressed mood (5), aggression (6), wandering (5), sexual disinhibition (2), emotional lability (2). Before 1988, the ward was a 16 bedded male ward for the physically frail and offered a homely but custodial environment for patients 51-71 years. This group was an uneasy mixture of long-stay graduates of the hospital and patients with organic brain syndromes from the admission wards. Nursing morale was low as they felt that they were the "dumping ground" of the hospital and, at their request, a planning team was set up and the orientation of the ward changed to a neuropsychiatric rehabilitation unit for people under 65. The aim of Heddiw is a multidisciplinary, problem-orientated approach to treatment (Livingstone, 1990).

Eleven of the first $\mathbf{2 0}$ admissions to the unit have now been discharged: fostering (4), home + respite care (6), nursing home (1). The average length of admission is nine months. The bedding accommodation is divided into seven assessment and five respite beds.

Nursing morale has improved greatly since 1988 and, in addition to the in-patient service, the staff act in a consultative capacity to the local rehabilitation hospital. Heddiw fulfils an important need the neuropsychiatric rehabilitation of young brain damaged individuals showing challenging behaviour - and currently has seven patients on its waiting list for admission.

Should a similar service be provided in every district?

\section{Whitchurch Hospital \\ Park Road \\ Cardiff CF4 $7 X B$}

\section{P. L. HuCKLe \\ M. Evans \\ P. Williams}

\section{References}

Livingstone, M. G. (1990) Rehabilitation in neuropsychiatry. British Journal of Hospital Medicine, 44, 402-404.

SHAWCROSs, C. R. et al (1990) Who cares for the adult brain damaged - Hamble Ward revisited. Psychiatric Bulletin, $14,526-527$.

\section{Do we ride a paper tiger?}

\section{Dear Sirs}

I would invite readers to go through the agenda and minutes of the meetings of their Division of Psychiatry over the past 60 months, note the topics brought to discussion, and the decisions reached. Note also the actions taken in response to the decisions, and the time intervals between decisions and actions.

Did you notice a certain pattern? That perhaps the same issues were raised, with little variation and even less action, year after year. Does the monthly 